\title{
Development of a microfluidic confocal fluorescence detection system for the hyphenation of nano-LC to on-line biochemical assays
}

\author{
Ferry Heus • Martin Giera • Gerdien E. de Kloe • Dick van Iperen • Joost Buijs • \\ Tariq T. Nahar • August B. Smit • Henk Lingeman • Iwan J. P. de Esch • \\ Wilfried M. A. Niessen • Hubertus Irth • Jeroen Kool
}

Received: 8 July 2010 /Revised: 7 September 2010 /Accepted: 8 September 2010 / Published online: 25 September 2010

(C) The Author(s) 2010. This article is published with open access at Springerlink.com

\begin{abstract}
One way to profile complex mixtures for receptor affinity is to couple liquid chromatography (LC) on-line to biochemical detection (BCD). A drawback of this hyphenated screening approach is the relatively high consumption of sample, receptor protein and (fluorescently labeled) tracer ligand. Here, we worked toward minimization of sample and reagent consumption, by coupling nano-LC on-line to a light-
\end{abstract}

Electronic supplementary material The online version of this article (doi:10.1007/s00216-010-4210-x) contains supplementary material, which is available to authorized users.

F. Heus $\cdot$ M. Giera $\cdot$ J. Buijs $\cdot$ H. Lingeman $\cdot$ W. M. A. Niessen • H. Irth $\cdot$ J. Kool $(\bowtie)$

BioMolecular Analysis, Department of Chemistry and

Pharmaceutical Sciences, Faculty of Sciences,

VU University Amsterdam,

De Boelelaan 1083,

1081 HV Amsterdam, The Netherlands

e-mail: j.kool@few.vu.nl

G. E. de Kloe • I. J. P. de Esch

Medicinal Chemistry, Department of Chemistry and

Pharmaceutical Sciences, Faculty of Sciences,

VU University Amsterdam,

De Boelelaan 1083,

1081 HV Amsterdam, The Netherlands

D. van Iperen

Mechanical and Electronic Workshops, Faculty of Sciences,

VU University Amsterdam,

De Boelelaan 1083,

1081 HV Amsterdam, The Netherlands

T. T. Nahar • A. B. Smit

Molecular and Cellular Neurobiology, Center for Neurogenomics

and Cognitive Research, Neuroscience Campus,

VU University Amsterdam,

De Boelelaan 1085,

1081 HV Amsterdam, The Netherlands emitting diode (LED) based capillary confocal fluorescence detection system capable of on-line BCD with low-flow rates. In this fluorescence detection system, a capillary with an extended light path (bubble cell) was used as a detection cell in order to enhance sensitivity. The technology was applied to a fluorescent enhancement bioassay for the acetylcholine binding protein, a structural analog of the extracellular ligandbinding domain of neuronal nicotinic acetylcholine receptors. In the miniaturized setup, the sensitive and low void volume LED-induced confocal fluorescence detection system operated in flow injection analysis mode allowing the measurement of $\mathrm{IC}_{50}$ values, which were comparable with those measured by a conventional plate reader bioassay. The current setup uses $50 \mathrm{~nL}$ as injection volume with a carrier flow rate of $400 \mathrm{~nL} / \mathrm{min}$. Finally, coupling of the detection system to gradient reversed-phase nano-LC allowed analysis of mixtures in order to identify the bioactive compounds present by injecting $10 \mathrm{~nL}$ of each mixture.

Keywords Miniaturization - Acetylcholine binding protein - LED-based confocal fluorescence detection . Microfluidics $\cdot$ Bioassay

\begin{tabular}{|c|c|}
\hline \multicolumn{2}{|c|}{ Abbreviations } \\
\hline 4-APC & $\begin{array}{l}\text { 4-(2-(Trimethylammonio)ethoxy)benzenaminium } \\
\text { bromide }\end{array}$ \\
\hline AChBP & Acetylcholine binding protein \\
\hline $\mathrm{BCD}$ & Biochemical detection \\
\hline CFD & Confocal fluorescence detector \\
\hline DAHBA & $\begin{array}{l}\text { (E)-3-(3-(4-Diethylamino-2-hydroxybenzylidene)- } \\
\text { 3,4,5,6-tetrahydropyridin-2-yl)pyridine }\end{array}$ \\
\hline DMDCS & Dimethyldichlorosilane \\
\hline FA & Formic acid \\
\hline FD & Fluorescence detector \\
\hline
\end{tabular}




$\begin{array}{ll}\text { FIA } & \text { Flow injection analysis } \\ K_{\mathrm{d}} & \text { Dissociation constant } \\ \text { LED } & \text { Light-emitting diode } \\ \text { LC } & \text { Liquid chromatography } \\ \mathrm{MeOH} & \text { Methanol } \\ \mathrm{MS} & \text { Mass spectrometer } \\ \text { PMT } & \text { Photomultiplier tube } \\ \text { RBA } & \text { Radioligand-binding assay }\end{array}$

\section{Introduction}

In search of bioactive compounds, many exogenous natural products were demonstrated to have valuable starting points for medicinal chemistry. For this reason, there is a continuous effort to capture the available biodiversity, but for some natural products, the available extracts are very scarce, and consequently, only limited amounts are available for analysis. Liquid chromatography (LC) is the separation workhorse in the process of screening for bioactive compounds in complex mixtures. After separation, fractionation, and evaporation, the bioactivity of each fraction is analyzed. This traditional dereplication process is usually associated with many bottlenecks as it is laborious and time consuming, and often multiple iterative cycles are needed to identify and obtain the pure bioactive compounds. This requires large amounts of starting material.

By coupling LC to on-line biochemical detection (BCD) and mass spectrometry (MS), bioactive mixtures can be screened more rapidly and comprehensively as bioactive compounds are simultaneously identified and unknowns may be structurally elucidated [1-6]. When applied for the screening of receptor ligands, the LC effluent is continuously mixed with the assay compounds consisting of target receptor and a fluorescent tracer ligand that has an enhanced fluorescence yield in the receptor's binding pocket $[7,8]$. A fluorescence detector is then used for the BCD readout. Even though less amount of sample is needed for successful on-line BCD than for traditional dereplication processes, in many cases, still substantial amounts are required. Nano-LC offers a solution to this problem from the separation's perspective, but needs the on-line fluorescence BCD part also to be miniaturized.

As microfluidic technologies utilize highly miniaturized and complex chip-based systems, there is a general demand for miniaturized detection methods that are sensitive and selective, in particular also for fluorescence detection [9]. An example of this is laser-induced fluorescence detection [10], but costs for adequate lasers are high and excitation wavelengths are either fixed or only have a limited tunable wavelength range [11, 12].
LED-induced fluorescence has been utilized in specific cases for, e.g., cell based analysis [13] and has the advantage of easily interchangeable LEDs for a wider range of wavelengths. Other techniques rely on non-flowbased or non-LC flow-based detection in confocal fluorescence mode [14]. Often, microfluidic chip-based setups are used for both incubation/chemical reaction steps and for fluorescence readout [15-17]. A disadvantage in these setups can be the restriction in freely changing the incubation unit and detection readout, which can be overcome by separating the incubation chamber and the detection cell. As a non-chip-based detection cell, a stripped fused silica capillary is a good option [18], although the flow path in narrow capillaries is very narrow, which limits the sensitivity. Even when operated in confocal mode, the sensitivity is compromised unless the confocal optics are of high quality and the positioning of the confocal point is very accurate, which means that expensive setups are necessary. Implementation of a bubble cell capillary is able to overcome this limitation.

This study presents the development of a microfluidic LED-based confocal fluorescence detection (CFD) system, with a bubble cell capillary as detection cell, capable of monitoring fluorescence bioassays in a continuous lowflow format. In this way, reduction of reagent and sample consumption in an on-line biochemical analysis format can be achieved by decreasing the overall flow rates for the fluorescence-based on-line BCD. An advantage of the new microfluidic CFD with respect to other low-flow rate fluorescence detection methods is the adaptation for online BCD at very low-flow rates in combination with nanoLC. The chromatographic part of the system utilizes nanoLC separations at sub- $\mu \mathrm{L} / \mathrm{min}$ flow rates, which was coupled on-line to the microfluidic CFD. The detection system consisted of a LED, excitation and emission filters, a confocal lens, a photomultiplier tube, and a bubble cell capillary acting as a detector cell (Fig. 1). To demonstrate the applicability of the system developed, an on-line BCD methodology with a fluorescence enhancement bioassay of acetylcholine binding protein (AChBP) as receptor in conjunction with the in-house made fluorescent tracer ligand (E)-3-(3-(4-diethylamino-2-hydroxybenzylidene)3,4,5,6-tetrahydropyridin-2-yl)pyridine (DAHBA) [8] was applied. As a biochemical incubation chamber for the miniaturized AChBP bioassay, a microfluidic chip was employed. This chip was similar to a previously developed chip, which was used for a miniaturized enzymatic on-line BCD utilizing mass spectrometry as readout [19]. Since combining flows in the nanoliter per minute range often leads to laminar flows, special considerations of mixing procedures are required $[20,21]$. Therefore, we used a microfluidic chip for efficient mixing of the bioassay flows [19]. The chip provides both efficient mixing of the nano- 


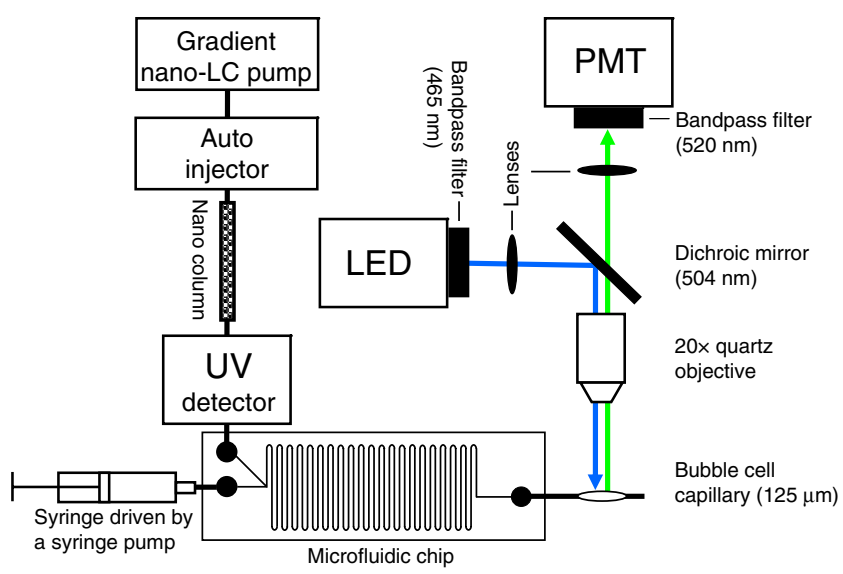

Fig. 1 Schematic view of the complete on-line microfluidic CFD system. The bioassay carrier solution was delivered by a syringe pump $(5 \mu \mathrm{L} / \mathrm{min})$ and mixed with the nano-LC effluent $(400 \mathrm{~nL} / \mathrm{min})$ in the $4-\mu \mathrm{L}$ reaction chamber of the microfluidic chip. A detailed photographic picture of the microfluidic chip can be found in de Boer et al. [19]. The outlet of the chip was hyphenated to the bubble cell capillary where fluorescence was detected by the PMT of the microfluidic CFD. A detailed description of the system is given in the "Experimental" section

LC effluent and the bioassay carrier flow and does so in a convenient and robust manner directing both flows to the CFD. When compared with traditional on-line bioaffinity systems $[8,22]$, the current setup not only allowed injection volumes of approximately a thousand times smaller but also decreased the overall flow rate of the bioassay $\sim 30$ times. This enabled the use of more convenient $2.5 \mathrm{~mL}$ syringes for continuous-flow bioassay delivery instead of $100 \mathrm{~mL}$ superloops operated by LC pumps.

$\mathrm{AChBP}$ is considered an analog for the ligand-binding domain of neuronal nicotinic acetylcholine receptors, which are potential pharmaceutical targets for Alzheimer's disease, Parkinson's disease, pain relief, anxiety, epilepsy, and several cognitive deficits [23-27]. These facts underline the importance of this target protein for drug discovery purposes.

\section{Experimental}

Chemical and biological reagents

AChBP (from snail species Lymnaea stagnalis) was expressed from Baculovirus using the pFastbac I vector in $\mathrm{Sf} 9$ insect cells and purified from the medium as described by Celie et al. [23]. The tracer ligand DAHBA, (E)-3-(3-(4-diethylamino2-hydroxybenzylidene)-3,4,5,6-tetrahydropyridin-2-yl)pyridine, was synthesized in-house [8]. $\mathrm{KH}_{2} \mathrm{PO}_{4}, \mathrm{Na}_{2} \mathrm{HPO}_{4}$, $\mathrm{NaCl}$, trizma base, hydrochloric acid, formic acid (FA), rhodamine-110, 5\% dimethyldichlorosilane (DMDCS) in toluene, and HPLC grade acetonitrile $(99.9 \%)$ were purchased from Sigma-Aldrich, Zwijndrecht, The Netherlands. ELISA blocking reagent was purchased from Roche, Mannheim, Germany. LC-MS grade methanol $(\mathrm{MeOH} ; 99.95 \%)$ was purchased from Biosolve, Valkenswaard, The Netherlands. HPLC grade water was produced using a Milli-Q purification system, Millipore, Amsterdam, The Netherlands. All ligands used for evaluating and validating the system were synthesized by the VU University Medicinal Chemistry department. The synthetic routes to compounds 1 and 7 were recently published by Kool and de Kloe et al. [8]. The synthetic route of compound 5 was recently published by Eggink et al. [28], referred to as 4-APC. The binding of compounds $2,3,4,6,8$, and 9 to AChBP was recently studied by De Kloe and Retra et al. [29]. The structures of all compounds including the tracer ligand DAHBA can be found in Fig. 2.

Instrumentation

The complete system consisted of a nano-LC unit including a UV detector, a microfluidic chip as biochemical reactor, and a microfluidic LED-based CFD (Fig. 1).

\section{Nano-LC and solvent delivery system}

The Ultimate nano-LC system with a Famos autosampler and UV detector was from LC Packings, Amsterdam, The Netherlands. The system was operated at $400 \mathrm{~nL} / \mathrm{min}$. Mobile phase solvent A consisted of water $/ \mathrm{MeOH} 95: 5$ and $0.1 \% \mathrm{FA}$; solvent $\mathrm{B}$ of water $/ \mathrm{MeOH} 5: 95$; and $0.1 \% \mathrm{FA}$. Sample volumes ranging from 10 to $50 \mathrm{~nL}$ were injected into the analytical capillary column (nano-LC; $150 \mathrm{~mm} \times$ $100 \mu \mathrm{m}$ i.d.) packed in-house with Waters Xbridge $\mathrm{C}_{18}$ particles $(5 \mu \mathrm{m}, 135 \AA$ pore diameter; Waters, Milford, MA, USA). For mixture analysis, gradient elution was applied running $15 \mathrm{~min}$ isocratic at $0 \%$ solvent $\mathrm{B}$, then rising to $75 \%$ solvent $\mathrm{B}$ in $45 \mathrm{~min}$. The column exit was coupled via a low void volume Z-shaped capillary (3 $\mathrm{nL}$ UV-detector cell) to the microfluidic chip and the CFD.

\section{Microfluidic chip}

The microfluidic chip and the 4515 chip holder were produced by Micronit Microfluidics, Enschede, The Netherlands, as described earlier [19] and shown schematically in Fig. 1 with all the interconnecting capillaries. Microchip ferrules were purchased from Upchurch Scientific, Oak Harbor, USA. The syringe pump was from Harvard Apparatus, Holliston, USA. Syringes were purchased from Hamilton AG, Bonaduz, Switzerland.

A schematic representation of the microfluidic chip is shown in Fig. 3. The $45 \times 15 \times 2.2 \mathrm{~mm}$ chip consisted of 
Fig. 2 Structures of the compounds/ligands used for validation and evaluation of the on-line microfluidic CFD bioaffinity system

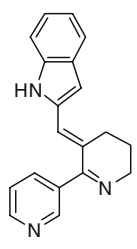

Compound 1

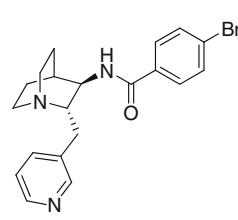

Compound 2

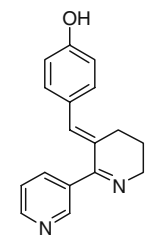

Compound 7

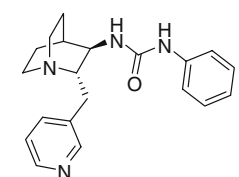

Compound 3

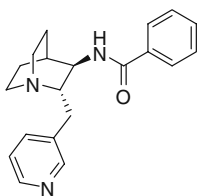

Compound 4

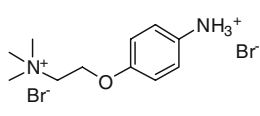

Compound 5

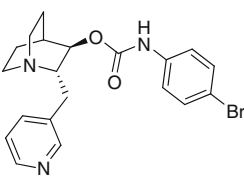

Compound 6

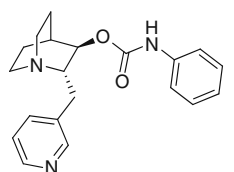

Compound 8

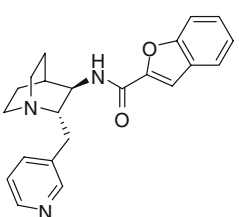

Compound 9<smiles>CCN(CC)c1ccc(/C=C2\CCCN=C2c2cccnc2)c(O)c1</smiles>

DAHBA two borofloat glass 33/D263 layers with a $457 \mathrm{~mm}$ long $\times$ $125 \mu \mathrm{m}$ wide and $70 \mu \mathrm{m}$ deep open tubular microreactor of $4 \mu \mathrm{L}$, comprising the total volume of the chip's channel. The reactor had two inlets and one outlet. One inlet was used to connect the nano-LC carrier flow; the other inlet was used to infuse the AChBP and tracer ligand DAHBA at a flow rate of $5 \mu \mathrm{L} / \mathrm{min}$ by a syringe pump. The chip outlet was connected to the microfluidic CFD.

All fused silica capillaries used for connections to and from the chip were purchased from BGB Analytik AG, Schloßböckelheim, Germany. A $300 \mathrm{~mm} \times 20 \mu \mathrm{m}$ internal diameter (i.d.) capillary connected the nano-LC system to the chip. The capillary connecting the syringe pump to the chip was deactivated by the supplier with 1,3-diphenyl1,1,3,3-tetramethyldisilazane and was $1,500 \mathrm{~mm} \times 50 \mu \mathrm{m}$ i.d. The outlet capillary to the bubble cell of the CFD was $1,000 \mathrm{~mm} \times 50 \mu \mathrm{m}$ i.d. The microchip, the $20 \mu \mathrm{m}$ i.d. capillary, and the bubble cell capillary were deactivated with

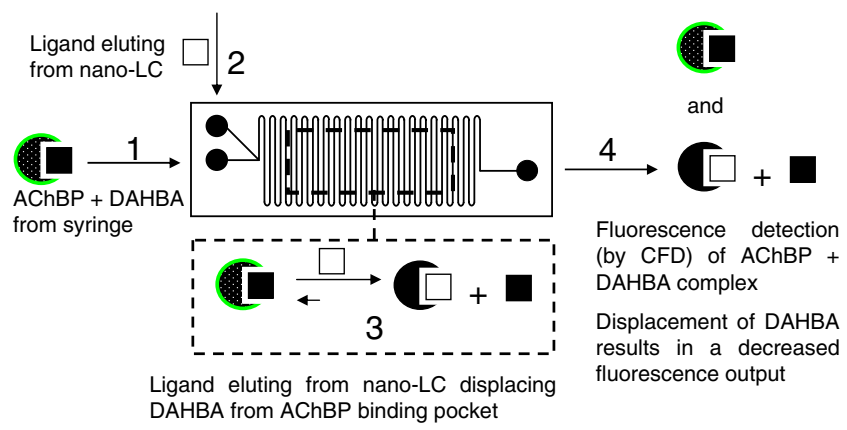

Fig. 3 The microfluidic chip, which comprises the bioaffinity analysis part of the system. AChBP and DAHBA are infused to the chip at $5 \mu \mathrm{L} / \mathrm{min}(1)$ together with the nano-LC effluent containing potential ligands (2). In the $4 \mu \mathrm{L}$ open tubular microreactor of the chip, DAHBA is displaced by eluting ligands from the analytical column (3) resulting in a decrease in fluorescence (4) as detected by the microfluidic CFD
5\% DMDCS in toluene as follows: The chip and the tubing were flushed with acetonitrile ( $5 \mathrm{~min}$ ), 5\% DMDCS (5 min), acetonitrile $(5 \mathrm{~min})$, and $\mathrm{MeOH}(5 \mathrm{~min})$ at a flow rate of $100 \mu \mathrm{L} / \mathrm{min}$ from a syringe pump.

\section{Microfluidic LED-based confocal fluorescence detector}

The microfluidic CFD is shown in detail in Fig. 1. The flow cell of the CFD consisted of a $150 \mu \mathrm{m}$ i.d. extended light path "bubble cell" with $50 \mu \mathrm{m}$ i.d. connecting capillaries (no. G1600-64232) and was purchased from Agilent Technologies, Amstelveen, The Netherlands. The LED (465 nm, $45 \mathrm{~mW}, 350 \mathrm{~mA}$; no. ELJ-465-211) was from Roithner Lasertechnik, Vienna, Austria. The quartz microscope objective $(20 \times 0.65$, working distance $2.0 \mathrm{~mm}$; no. 03-0202) was from Partec Optics, Münster, Germany. The photomultiplier tube, incorporated in a photosensor module (185- to $650 \mathrm{~nm}$ spectral response; no. H9656-03) was from Hamamatsu, Shuzuoka, Japan. Focusing lenses were from Bernhard Halle Nachfl. $\mathrm{GmbH}$, Berlin, Germany. The dichroic mirror (506 nm; no. FF506-Di02-25) and bandpass filters (465 nm and $520 \mathrm{~nm}$; no. FF01-465/30-25 and FF01-520/35-25) were from Semrock, Rochester, USA.

In the CFD, the bubble cell serves as the actual flowthrough detector cell. Light emanating from the highintensity LED passed through the $465 \mathrm{~nm}$ single bandpass filter, after which it was collimated by a lens and reflected under $90^{\circ}$ by the dichroic mirror. The filtered light was subsequently focused into the center of the $150 \mu \mathrm{m}$ bubble cell by the $20 \times$ quartz microscope objective. Emitted light then passed the same dichroic mirror, a focusing lens, and the $520 \mathrm{~nm}$ single bandpass filter and was subsequently detected by the photomultiplier tube. The LASER ( $473 \mathrm{nM}$, $10 \mathrm{~mW}$, DPSS RLTMBL) used in the initial setup was also from Roithner Lasertechnik. 
Hardware optimization and chemical evaluation

\section{Signal-to-noise determinations of the microfluidic CFD at different settings}

At each photomultiplier tube (PMT) control voltage (8.0 to $10.0 \mathrm{~V}$ at $0.5 \mathrm{~V}$ increments tested) and four different LED input currents (from 200 to $350 \mathrm{~mA}$ at $50 \mathrm{~mA}$ increments), baselines were recorded at a frequency of $10 \mathrm{~Hz}$ for $1 \mathrm{~min}$, while infusing a water/MeOH 50:50 solution to the microfluidic CFD with the syringe pump operated at $5 \mu \mathrm{L} / \mathrm{min}$. The noise of the CFD system at each specific condition was calculated as two times the standard deviation of the 600 data points measured. In order to obtain a fluorescence signal, the above-described measurements were repeated with infusion of rhodamine- 110 at a concentration of $500 \mathrm{pM}$. The measured 600 data points at each specific condition were averaged. Thus, the signal-to-noise ratio for $500 \mathrm{pM}$ rhodamine-110 at five different PMT control voltages and four LED input currents were calculated.

\section{Linearity analysis of the microfluidic CFD}

To evaluate linearity at the 20 conditions tested as described for the signal-to-noise calculation, rhodamine-110 solutions were infused with concentrations of $0,0.5,1.0,2.5,5.0$, 10.0 , and $25 \mathrm{nM}$ in water/MeOH 50:50. The resulting rhodamine-110 baselines were averaged for data analysis.

\section{Determination of $I C_{50}$ values with the microfluidic CFD operated as on-line $B C D$}

Nano-column based flow injection analysis (FIA) in a concentration-response manner allowed the determination of $\mathrm{IC}_{50}$ values of test compounds. These analyses were run in isocratic LC mode with $0 \%$ to $50 \% \mathrm{~B}$ in the mobile phase, depending on the lipophilicity of each investigated compound. Each compound eluted from the nano-column without retention.

\section{AChBP biochemical bioassay}

Fresh solutions of L. stagnalis Acetylcholine binding protein (AChBP) and the fluorescent tracer ligand DAHBA were made every day by dissolving $1 \mu \mathrm{g} / \mathrm{mL}$ AChBP and $40 \mathrm{nM}$ DAHBA in the bioassay solution containing: $1 \mathrm{mM}$ $\mathrm{KH}_{2} \mathrm{PO}_{4}, 3 \mathrm{mM} \mathrm{Na}_{2} \mathrm{HPO}_{4}, 0.16 \mathrm{mM} \mathrm{NaCl}, 20 \mathrm{mM}$ trizma base $/ \mathrm{HCl}$ at $\mathrm{pH} 7.5$ and $400 \mu \mathrm{g} / \mathrm{mL}$ ELISA blocking reagent. The bioassay solution was housed in a $2.5 \mathrm{~mL}$ syringe. During the experiments, the AChBP/DAHBA bioassay solution in the syringe was kept at $4{ }^{\circ} \mathrm{C}$. The online bioassay itself was performed at $22{ }^{\circ} \mathrm{C}$. The syringe pump was operated at a flow rate of $5 \mu \mathrm{L} / \mathrm{min}$. The resulting bioassay flow was mixed with the eluent from the nano-LC. Continuous in-flow incubation was allowed in the microfluidic chip and then followed by fluorescence detection with the microfluidic CFD.

\section{Results and discussion}

Evaluation of the on-line microfluidic confocal fluorescence detection system

\section{Hardware setup}

The microfluidic CFD setup initially contained a laser as light source. Although the light beam from the laser tested (from Roithner Lasertechnik, $473 \mathrm{nM}, 10 \mathrm{~mW}$, DPSS RLTMBL) was more focused, and therefore more powerful than the LED used in the rest of this study, it also had serious drawbacks. Besides the higher costs, lasers as a light source impose restrictions as they only allow one wavelength (or a limited range) per laser to be used. Furthermore, baseline stability and reproducibility of the tested laser were not adequate for our purposes. Due to these drawbacks, the LED clearly surpasses the tested laser as LEDs are cheap and available in a large variety of wavelengths. More importantly, they were found to produce a more stable and reproducible fluorescence detection system for our purposes. Therefore, a LED was incorporated into the system together with an additional collimating lens to focus the light of the LED. In order to evaluate and optimize sensitivity and performance of the detection, capillaries with $20,50,100$, and $150 \mu \mathrm{m}$ i.d. as well as two types of bubble cell capillaries were evaluated as detection cell by installing the capillaries into the CFD, followed by infusion of a rhodamine-110 solution. In these experiments, an excitation wavelength of $465 \mathrm{~nm}$ was applied. A detection window was created in the tested capillaries (except the bubble cell capillaries) by locally removing the polyimide coating. The 100 and $150 \mu \mathrm{m}$ i.d. capillaries yielded higher fluorescence signals than the 20 or $50 \mu \mathrm{m}$ i.d. capillaries, which rendered the fluorescence system rather insensitive due to the very limited light path. An evident drawback of the two larger i.d. capillaries as detector cells was the increased dead volume, which imposed problems upon implementation into the miniaturized flow system. Besides sensitivity issues, the $20 \mu \mathrm{m}$ capillary was also very susceptible to clogging; therefore, capillaries with an i.d. smaller than $50 \mu \mathrm{m}$ i.d. were not evaluated further. Next, two bubble cell capillaries [30] were evaluated. Both 50 and $75 \mu \mathrm{m}$ i.d. capillaries (with a 150 and $200 \mu \mathrm{m}$ bubble cell, respectively) were tested. Although the $75 \mu \mathrm{m}$ i.d. capillary showed a slightly higher signal-to-noise ratio than the $50 \mu \mathrm{m}$ i.d. capillary, the $50 \mu \mathrm{m}$ i.d. bubble cell capillary 
was finally incorporated in the system. The $50 \mu \mathrm{m}$ i.d. capillary part did not significantly increase the system dead volume (and thus band broadening), while the advantage of the bubble cell to provide an extended light path yielded a fluorescence readout with a 5.6 times increased sensitivity compared with the $50 \mu \mathrm{m}$ i.d. capillary without a bubble cell. This was in good agreement with the six times' increase in sensitivity as given by the supplier.

\section{Electronic settings (LED intensity and PMT control voltage)}

The final microfluidic CFD hardware setup was subsequently evaluated by measuring the fluorescence of a blank and a $500 \mathrm{pM}$ rhodamine- 110 solution at 20 different combinations of LED and PMT settings. The results obtained are shown in Fig. S1 (Electronic supplementary material). The optimal signal-to-noise ratio was found at a power input to the LED of $350 \mathrm{~mA}$ and the control voltage of the PMT set at a value of $10 \mathrm{~V}$, which were both the maximal settings. The signal-to-noise ratio of $500 \mathrm{pM}$ rhodamine-110 was found to be 23 at these settings. Next, the linearity was evaluated by infusing different concentrations $(0.5$ to $25 \mathrm{nM})$ of rhodamine-110 at the optimal settings. From these results (Fig. S2: Electronic supplementary material), it was concluded that the system showed a high linearity at the optimal settings within the concentration range tested. These results also showed a dynamic range from 0.5 to $25 \mathrm{nM}$ rhodamine-110 with an $R^{2}$ of 0.9998. Concentrations higher than $25 \mathrm{nM}$ showed similar linearity, but could only be measured by decreasing the voltage to the PMT.

Biological evaluation and validation of the microfluidic confocal fluorescence detection system operated in on-line biochemical detection mode

\section{Initial biochemical evaluation}

The miniaturized on-line bioaffinity analysis part of the system is shown in Fig. 3. DAHBA and AChBP are continuously infused into the chip where the bioassay carrier solution is mixed continuously with the nano-LC eluent. Injected compounds elute from the nano-LC column to the chip where they are allowed to incubate with the miniaturized bioassay. In the incubation chamber of the chip, ligands displace DAHBA from the AChBP binding pocket. As this displacement results in a decreased fluorescence yield from DAHBA, it is detected by the microfluidic CFD as a negative peak in the on-line bioassay trace. The concentration (of $1 \mu \mathrm{g} / \mathrm{mL}$ ) AChBP was chosen to allow a good assay window while maintaining optimal bioassay sensitivity. The concentration of tracer DAHBA used (40 nM) was slightly higher than its dissociation constant $\left(K_{\mathrm{d}}\right)$ [8]. This is commonly done for ligandbinding assays. The optimal flow rate of the bioassay carrier solution was determined by varying the flow rate with incremental steps of $1 \mu \mathrm{L} / \mathrm{min}$, starting at $1 \mu \mathrm{L} / \mathrm{min}$. A stable baseline was observed at a minimal flow rate of $5 \mu \mathrm{L} / \mathrm{min}$. At this flow rate, the syringe pump generated no pulses, nor did the $75 \% \mathrm{MeOH}$ and $0.1 \%$ FA in the nanoLC effluent have any adverse effects on the bioassay. Higher flow rates of the bioassay carrier solution had a negative effect on the bioassay sensitivity because of dilution effects. During the initial biochemical evaluation and after test injections of AChBP ligands, a decline in assay sensitivity was observed. This was due to the adsorption of AChBP to the wall of the chip and bubble cell capillary, causing clogs, tailing effects, and an increased baseline. Therefore, a DMDCS deactivation procedure was applied to the chip, connecting capillaries and the bubble cell. With deactivated capillaries, no significant (increases in) band broadening were observed during a time period of 3 months. Also, a more stable baseline was observed and no clogging occurred anymore.

\section{Biochemical validation}

Nicotine, a typical ligand for AChBP, was used to evaluate intraday and interday repeatability of the complete system. Nicotine was injected at increasing concentrations, with a nano-LC carrier flow containing $0 \%$ eluent $\mathrm{B}$, which allowed nicotine to elute from the column non-retained. A typical analysis result is shown in Fig. 4. The figure shows the displacement profile of $50 \mathrm{~nL}$ of nicotine injected in triplicate at 12 different concentrations in a serial dilution manner with a factor of two. Injecting different concentrations of nicotine showed negative peaks of which the negative peak heights represented the percentage of DAHBA displaced in the bioassay. Over $99 \%$ tracer DAHBA displacement by nicotine occurred at a concentration of $10 \mu \mathrm{M}$ of nicotine in the bioassay. At full DAHBA displacement, injecting higher nicotine concentrations evidently did not yield higher negative signals, but only broader signals due to tailing effects. The figure also indicates the excellent repeatability for each concentration injected.

The intraday repeatability was determined by measuring multiple $\mathrm{IC}_{50}$ curves during one measuring day using the same batch of bioassay constituents. Because ligands injected are diluted in the microfluidic BCD system, a dilution factor has to be used to correlate DAHBA displacements with the actual ligand concentrations in the on-line BCD part. Therefore, a dilution factor was calculated in order to determine $\mathrm{IC}_{50}$ values. This was done according to a mathematical analytical formula as 


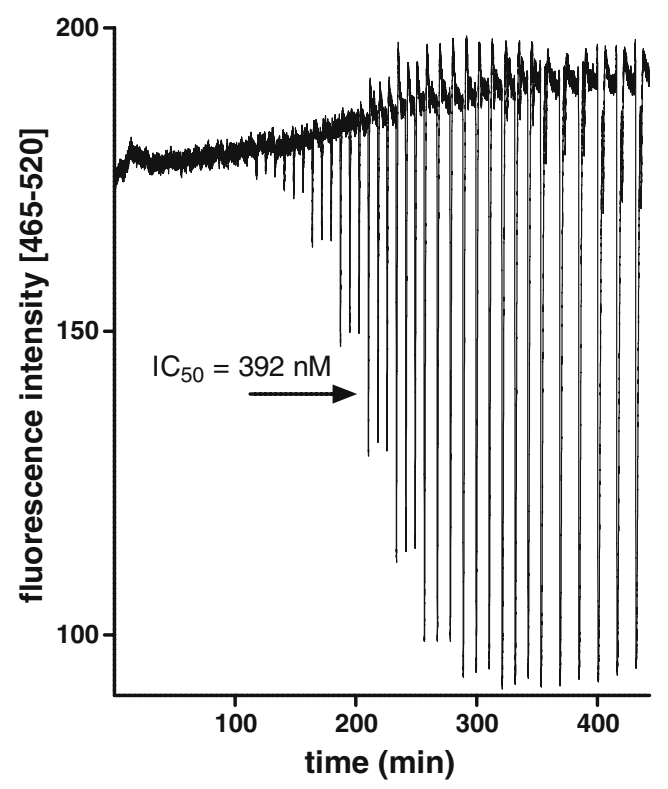

Fig. 4 Triplicate injections $(50 \mathrm{~nL})$ of increasing concentrations (100 $\mathrm{nM}$ to $10 \mathrm{mM}$, in-vial concentration) of the ligand nicotine in FIA mode. The observed negative peak heights were plotted against the concentrations inside the flow system to obtain an $\mathrm{IC}_{50}$ curve; see Fig. 5 for the $\mathrm{IC}_{50}$ curve of nicotine

presented previously [22, 31] (see also the Electronic supplementary material for the formula used and further explanation) and resulted in a dilution factor of 243 , which was used further. Table 1 shows the analytical results. These results demonstrate that the system operated in a very repeatable manner $(\mathrm{RSD}=1.5 \%)$. Furthermore, the average $\mathrm{IC}_{50}$ for nicotine as acquired from the $\mathrm{IC}_{50}$ curve shown in Fig. 5 (6.41), correlated well with results obtained by traditional biochemical assay formats $(6.40$; from Kool et al. [8]). The bioassay window was determined as the largest negative peak obtainable and was measured by injecting a very high concentration of nicotine. The bioassay window did not change markedly over a full measuring day. As seen in Fig. 4, representing a typical measuring result, a small baseline drift (of only $8 \%$ in this case) was observed during $7 \mathrm{~h}$.
The interday reproducibility was tested in essentially the same way as the intraday repeatability, but in this case, one $\mathrm{IC}_{50}$ curve was measured per day with every day a fresh solution of bioassay constituents for 3 days. These results are depicted in Table 1 and Fig. S3 (Electronic supplementary material) and clearly show the good reproducibility of the system $(\mathrm{RSD}=2.3 \%)$. This was also the case for the bioassay window that did not show marked differences over the days; an average assay window (maximum obtainable $S / N$ ratio) of $47.2 \pm 1.7$ was found. As the average $\mathrm{IC}_{50}$ found $\left(\mathrm{IC}_{50}\right.$ of $\left.6.38 \pm 0.02\right)$ for nicotine (see Table 1) correlated well with results obtained by a traditional radioligand-binding assay (RBA; $\mathrm{IC}_{50}$ of $6.40 \pm 0.01$ ) [8] and low standard deviations were obtained, it was concluded that the methodology was not only accurate but also precise.

The results from both the repeatability as well as the reproducibility experiments allowed us to further validate the system by analyzing several ligands for a pharmacological comparison with traditional methodologies.

\section{Pharmacological validation}

To evaluate the biological sensitivity and validate the system pharmacologically, $\mathrm{IC}_{50}$ values of different ligands were measured the same way as done for the intraday repeatability and then compared with results from a traditional RBA. For this, five ligands including nicotine were analyzed. The structures of the ligands used can be found in Fig. 2. These quinuclidine-containing ligands were chosen because their binding to $\mathrm{AChBP}$ has been properly characterized [29]. After analysis of the ligands with both FIA on-line microfluidic BCD and with a traditional RBA, $\mathrm{IC}_{50}$ curves were constructed (see Fig. 5 for the on-line microfluidic BCD FIA measurements). Subsequently, a correlation plot was constructed by plotting the CFD $\mathrm{p} K_{\mathrm{i}}$ values to the $\mathrm{p} K_{\mathrm{i}}$ values of a traditional RBA. The $R^{2}$ of this plot then rates the applicability of the system to assess ligand binding. The model equation derived from Fig. 6 was $y=0.696 x+2.1455$ with an $R^{2}=0.9651$ (Fig. 6). The correlation between results from our microfluidic system

Table 1 Pharmacological validation by evaluation of the intraday repeatability and interday reproducibility

\begin{tabular}{llllll}
\hline Parameter & $1\left(p \mathrm{IC}_{50}\right)$ & $R^{2}$ & $2\left(p \mathrm{IC}_{50}\right)$ & $R^{2}$ & $3\left(p \mathrm{IC}_{50}\right)$ \\
\hline Intraday $^{\mathrm{a}}$ & $6.41 \pm 0.02$ & 0.9973 & $6.55 \pm 0.02$ & 0.9932 & n.d. \\
Interday $^{\mathrm{b}}$ & $6.07 \pm 0.01$ & 0.9989 & $6.35 \pm 0.01$ & 0.9988 & $6.21 \pm 0.02$ \\
\hline
\end{tabular}

The numbers 1,2 , and 3 signify the respective measurements

${ }^{a}$ The intraday repeatability was investigated by determining the $\mathrm{IC}_{50}$ value of nicotine two times in triplicate within $24 \mathrm{~h}$

${ }^{\mathrm{b}}$ For the interday repeatability, the $\mathrm{IC}_{50}$ value of nicotine was determined three times in triplicate over the course of 3 days 


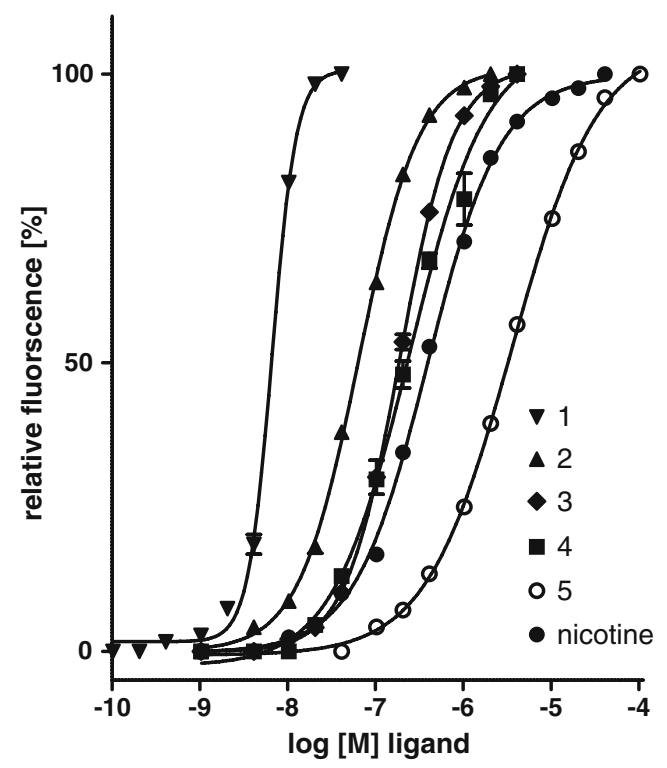

Fig. $5 \mathrm{IC}_{50}$ curves of six AChBP ligands. All ligands were injected in triplicate with an injection volume of $50 \mathrm{~nL}$

and traditional RBA demonstrated the excellent applicability of the microfluidic $\mathrm{BCD}$ system for $\mathrm{IC}_{50}$ determination of ligands. The system also proved to be very sensitive; the LOD of compound $1\left(\mathrm{p} K_{\mathrm{i}}\right.$ of $\left.8.71 \pm 0.03\right)$ for example was $412 \mathrm{pM}$. In addition, compound 5 with a choline moiety that we used as derivatization reagent in previous work [28] was also investigated with the complete system. This was done because it was expected that this compound also had affinity toward the AChBP as the choline moiety represents

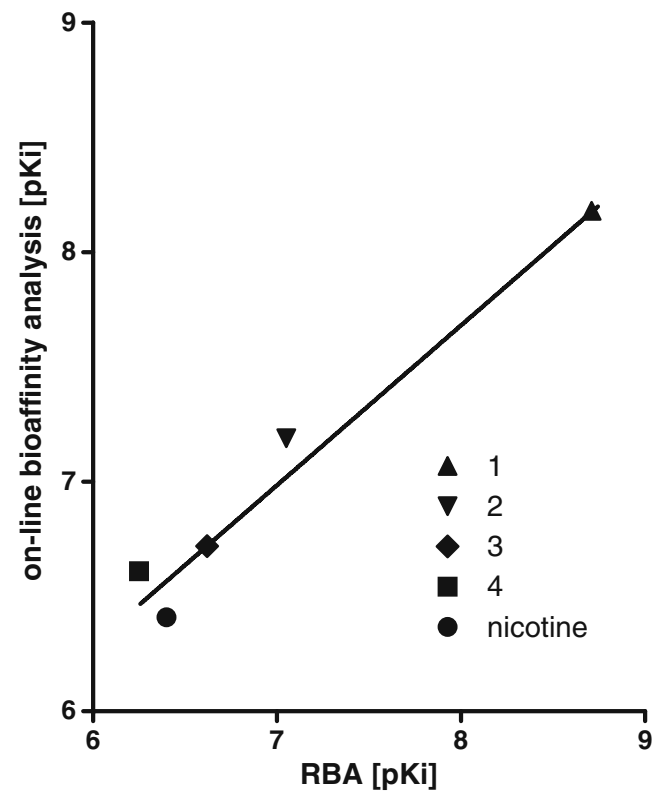

Fig. 6 Correlation plot of five typical ligands analyzed with both the traditional RBA and the on-line microfluidic BCD. An $R^{2}$ of 0.9651 was obtained an important pharmacophoric part for AChBP binding pocket. Indeed, compound 5 showed a low affinity $\left(\mathrm{p} K_{\mathrm{i}}\right.$ of $5.45 \pm 0.01$ ) toward AChBP.

Proof-of-principle for mixture analysis of the microfluidic confocal fluorescence system

To show the potential of the microfluidic CFD for bioaffinity analysis of mixtures toward the AChBP, a mixture of eight ligands was separated by nano-LC followed by biochemical analysis with the miniaturized BCD format. A typical result obtained is shown in Fig. 7. For analysis of the mixture shown, only $10 \mathrm{~nL}$ of mixture was injected. The upper trace shows an UV readout at $254 \mathrm{~nm}$ of the eight ligands injected (100 pmol injected). The lower trace shows the simultaneously obtained bioaffinity trace. This trace clearly shows displacement of the DAHBA tracer ligand from the AChBP binding pocket upon eluting ligands, yielding negative peaks indicative of the total bioaffinity per ligand separated. The miniaturized system shows a very stable baseline, while bioaffinity peaks are obtained with very low band broadening effects. The system's stability and low band broadening in the UV trace as well as in the bioassay enable a clear distinction between co-eluting compounds as can be seen for compounds 3,7 and 8. The UV trace in Fig. 7 shows an excellent separation for these closely related analogs. These results also indicate that the miniaturized system could be used to establish

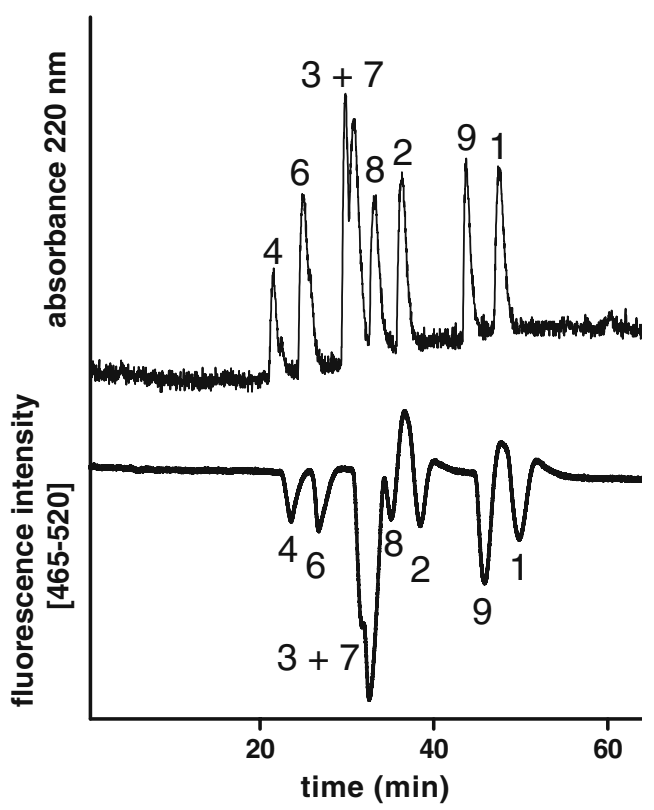

Fig. 7 On-line microfluidic BCD and UV analysis of a mixture containing eight $\mathrm{AChBP}$ ligands $(10 \mathrm{~nL}$ injected). The upper trace shows the UV signal of the ligands. The lower trace shows the fluorescence bioaffinity signal, as obtained by the microfluidic CFD. Structures of the ligands are shown in Fig. 2 
structure-activity relationships, for this implies the evaluation of different substituents on one scaffold.

Both the $\mathrm{IC}_{50}$ measurements of pure compounds as well as the application of bioactive mixture analysis demonstrate that this miniaturized system is comparable in terms of sensitivity and stability with "non-miniaturized" on-line BCD systems where much higher flow rates and injection volumes are used $[7,8,31]$. Here, the additional advantage of our new miniaturized BCD technology is the use of very low sample volumes in a fluorescence-based detection setup. This renders the setup suitable for analysis of very scarce and/or precious samples, which is a topic of our current research efforts.

\section{Conclusion}

A microfluidic CFD was developed and successfully coupled to a miniaturized continuous-flow bioassay incorporating a nano-LC system as the separation technology. The implementation of a LED and a DMDCS deactivation procedure made the system stable, rugged, and very versatile for, e.g., on-line biochemical screening utilizing fluorescent tracer ligands with different fluorescence properties. Additional sensitivity was obtained by the implementation of a bubble cell capillary as detection cell. The presented system not only showed a very good stability and robustness but also decreased sample consumption a thousand fold as compared with conventional on-line systems. By miniaturizing both the overall flow rates of the system from the micro- to the nano-scale and the dimensions used in the flow system, a miniaturized continuous-flow system was obtained. Here, the enormous reduction in consumption of sample and biochemical reagents provides for a larger range in possible drug targets for on-line bioactivity screening, which are for example difficult to produce or obtain in larger quantities. Furthermore, the system allows chemical and simultaneous biochemical screening of scarce sample types only obtainable in very low volumes, such as precious natural extracts, animal venoms, cell, and tissue lysates. By miniaturizing, no stability and sensitivity were sacrificed when compared with conventional on-line systems.

\section{Acknowledgements This work was financially supported by ECHO grant no. 700.56.043 from the Dutch Scientific Society NWO. Martin Giera was supported by the German Academic Exchange Service (DAAD). Gerdien E. de Kloe and Tariq T. Nahar were financially supported within the framework of Top Institute Pharma no. D2-103. Ansgar Kretschmer is thanked for suggesting 4-APC as a possible AChBP ligand.}

Open Access This article is distributed under the terms of the Creative Commons Attribution Noncommercial License which permits any noncommercial use, distribution, and reproduction in any medium, provided the original author(s) and source are credited.

\section{References}

1. Johnson BM, Nikolic D, van Breemen RB (2002) Applications of pulsed ultrafiltration-mass spectrometry. Mass Spectrom Rev 21 (2):76-86

2. Sun Y, Gu C, Liu X, Liang W, Yao P, Bolton JL, van Breemen RB (2005) Ultrafiltration tandem mass spectrometry of estrogens for characterization of structure and affinity for human estrogen receptors. J Am Soc Mass Spectrom 16(2):271-279

3. Niessen KV, Hofner G, Wanner KT (2005) Competitive ms binding assays for dopamine $\mathrm{d} 2$ receptors employing spiperone as a native marker. Chembiochem 6(10):1769-1775

4. Annis DA, Nazef N, Chuang CC, Scott MP, Nash HM (2004) A general technique to rank protein-ligand binding affinities and determine allosteric versus direct binding site competition in compound mixtures. J Am Chem Soc 126(47):15495-15503

5. Kool J, Eggink M, van Rossum H, van Liempd SM, van Elswijk DA, Irth H, Commandeur JN, Meerman JH, Vermeulen NP (2007) Online biochemical detection of glutathione-s-transferase p1specific inhibitors in complex mixtures. J Biomol Screen 12 (3):396-405

6. Kool J, Van Liempd SM, Harmsen S, Schenk T, Irth H, Commandeur JN, Vermeulen NP (2007) An on-line post-column detection system for the detection of reactive-oxygen-speciesproducing compounds and antioxidants in mixtures. Anal Bioanal Chem 388(4):871-879

7. Oosterkamp AJ, Villaverde Herraiz MT, Irth H, Tjaden UR, van der Greef J (1996) Reversed-phase liquid chromatography coupled on-line to receptor affinity detection based on the human estrogen receptor. Anal Chem 68(7):1201-1206

8. Kool J, de Kloe GE, Bruyneel B, de Vlieger JS, Retra K, Wijtmans M, van Elk R, Smit AB, Leurs R, Lingeman H, de Esch IJ, Irth H (2010) Online fluorescence enhancement assay for the acetylcholine binding protein with parallel mass spectrometric identification. J Med Chem 53(12):4720-4730

9. Gotz S, Karst U (2007) Recent developments in optical detection methods for microchip separations. Anal Bioanal Chem 387 (1):183-192

10. Laing TD, Marenco AJ, Moore DM, Moore GJ, Mah DC, Lee WE (2006) Capillary electrophoresis laser-induced fluorescence for screening combinatorial peptide libraries in assays of botulinum neurotoxin a. J Chromatogr B Analyt Technol Biomed Life Sci 843(2):240-246

11. Kolivoska V, Weiss VU, Kremser L, Gas B, Blaas D, Kenndler E (2007) Electrophoresis on a microfluidic chip for analysis of fluorescence-labeled human rhinovirus. Electrophoresis 28 (24):4734-4740

12. Yu L, Shen Z, Mo J, Dong X, Qin J, Lin B (2007) Microfluidic chip-based cell electrophoresis with multipoint laser-induced fluorescence detection system. Electrophoresis 28(24):4741-4747

13. Tatosian DA, Shuler ML, Kim D (2005) Portable in situ fluorescence cytometry of microscale cell-based assays. Opt Lett 30(13):1689-1691

14. Sung JH, Kam C, Shuler ML (2010) A microfluidic device for a pharmacokinetic-pharmacodynamic (pk-pd) model on a chip. Lab Chip 10(4):446-455

15. Hadd AG, Raymond DE, Halliwell JW, Jacobson SC, Ramsey JM (1997) Microchip device for performing enzyme assays. Anal Chem 69(17):3407-3412

16. Kong J, Jiang L, Su X, Qin J, Du Y, Lin B (2009) Integrated microfluidic immunoassay for the rapid determination of clenbuterol. Lab Chip 9(11):1541-1547

17. Fonseca A, Raimundo IM Jr, Rohwedder JJ, Lima RS, Araujo MC (2010) A microfluidic device with integrated fluorimetric detection for flow injection analysis. Anal Bioanal Chem 396(2):715-723 
18. Du WB, Fang Q, Fang ZL (2006) Microfluidic sequential injection analysis in a short capillary. Anal Chem 78(18):64046410

19. de Boer AR, Bruyneel B, Krabbe JG, Lingeman H, Niessen WM, Irth H (2005) A microfluidic-based enzymatic assay for bioactivity screening combined with capillary liquid chromatography and mass spectrometry. Lab Chip 5(11):1286-1292

20. Auroux PA, Iossifidis D, Reyes DR, Manz A (2002) Micro total analysis systems. 2. Analytical standard operations and applications. Anal Chem 74(12):2637-2652

21. Burke BJ, Regnier FE (2003) Stopped-flow enzyme assays on a chip using a microfabricated mixer. Anal Chem 75(8):17861791

22. Falck D, de Vlieger JS, Niessen WM, Kool J, Honing M, Giera M, Irth H (2010) Development of an online p38alpha mitogenactivated protein kinase binding assay and integration of LC-HRMS. Anal Bioanal Chem. doi:10.1007/s00216-010-4087-8

23. Celie PH, Kasheverov IE, Mordvintsev DY, Hogg RC, van Nierop $\mathrm{P}$, van Elk R, van Rossum-Fikkert SE, Zhmak MN, Bertrand D, Tsetlin V, Sixma TK, Smit AB (2005) Crystal structure of nicotinic acetylcholine receptor homolog achbp in complex with an alpha-conotoxin pnia variant. Nat Struct Mol Biol 12(7):582588

24. Dutertre S, Ulens C, Buttner R, Fish A, van Elk R, Kendel Y, Hopping G, Alewood PF, Schroeder C, Nicke A, Smit AB, Sixma TK, Lewis RJ (2007) Achbp-targeted alpha-conotoxin correlates distinct binding orientations with nachr subtype selectivity. EMBO J 26(16):3858-3867
25. Hogg RC, Bertrand D (2004) Nicotinic acetylcholine receptors as drug targets. Curr Drug Targets CNS Neurol Disord 3(2):123-130

26. Hogg RC, Raggenbass M, Bertrand D (2003) Nicotinic acetylcholine receptors: from structure to brain function. Rev Physiol Biochem Pharmacol 147:1-46

27. Smit AB, Syed NI, Schaap D, van Minnen J, Klumperman J, Kits KS, Lodder H, van der Schors RC, van Elk R, Sorgedrager B, Brejc K, Sixma TK, Geraerts WP (2001) A glia-derived acetylcholine-binding protein that modulates synaptic transmission. Nature 411(6835):261-268

28. Eggink M, Wijtmans M, Ekkebus R, Lingeman H, de Esch IJ, Kool J, Niessen WM, Irth H (2008) Development of a selective esi-ms derivatization reagent: synthesis and optimization for the analysis of aldehydes in biological mixtures. Anal Chem 80(23):9042-9051

29. de Kloe GE, Retra R, Geitmann M, Källblad P, Nahar T, van Elk $\mathrm{R}$, Smit AB, van Muijlwijk-Koezen JE, Leurs R, Irth $\mathrm{H}$, Danielson UH, de Esch IJP (2010) Surface plasmon resonance biosensor based fragment screening using acetylcholine binding protein identifies ligand efficiency hot spots (le hot spots) by deconstruction of nicotinic acetylcholine receptor $\alpha 7$ ligands. J Med Chem. doi:10.1021/jm100834y

30. Hempel G (2000) Strategies to improve the sensitivity in capillary electrophoresis for the analysis of drugs in biological fluids. Electrophoresis 21(4):691-698

31. Schebb NH, Heus F, Saenger T, Karst U, Irth H, Kool J (2008) Development of a countergradient parking system for gradient liquid chromatography with online biochemical detection of serine protease inhibitors. Anal Chem 80(17):6764-6772 